\title{
Clinical, Biochemical, and Radiologic Characteristics of Filipino Patients with Glutaric Aciduria Type 1
}

\author{
Ebner Bon G. Maceda, ${ }^{1,2}$ Mary Ann R. Abacan ${ }^{1,2}$ and Mary Anne D. Chiong ${ }^{1,2}$ \\ ${ }^{1}$ Division of Clinical Genetics, Department of Pediatrics, College of Medicine and Philippine General Hospital, University of the Philippines Manila \\ ${ }^{2}$ Institute of Human Genetics, National Institutes of Health, University of the Philippines Manila
}

\begin{abstract}
Introduction. Glutaric Aciduria Type 1 (GA1) is an inborn error of metabolism included in the expanded newborn screening of the Philippines. This inborn error of metabolism is caused by glutaryl-CoA dehydrogenase deficiency which is important in the catabolism of lysine, hydroxylysine and tryptophan.
\end{abstract}

Objective. This paper aimed to present the baseline data of patients with GA1 in the Philippines by describing the clinical, biochemical, and radiologic characteristics of Filipino patients with biochemically-confirmed GA1 seen at the Philippine General Hospital from January 2010 to December 2017. The cases of this condition have been increasing and are expected to increase even more with the full coverage of the expanded newborn screening.

Methods. This study was a review of the medical records of the GA1 patients managed by the Division of Clinical Genetics, Department of Pediatrics of the Philippine General Hospital (PGH). Biochemical parameters, developmental assessment, neurologic assessment, and radiologic features of the patients were reviewed and analyzed.

Results. There were a total of 7 patients with GA1 at the PGH from January 2010 to December 2017. Of the 7 patients, 4 were diagnosed by expanded newborn screening (ENBS) and 3 patients had disease onset prior to diagnosis. Clinical features noted in screened patients include global developmental delay (75\%), seizures (50\%), dystonia (50\%), truncal hypotonia (25\%) and macrocephaly (25\%). In unscreened patients, macrocephaly was present in $66.67 \%$, while the other clinical features were present in all of them. Four of the 7 patients had infection and one had vaccination, which may have led to a metabolic crisis and subsequent onset of symptoms. The plasma levels of glutarylcarnitine (C5DC) range from 2.81 to 4.58 umol/L. Grossly elevated urinary excretion of glutarylcarnitine were noted in all patients. Urinary glutaconic acid and 3-hydroxyglutaric acid were also detected in all patients. Both striatal and extra-striatal abnormalities were present in screened and unscreened patients on neuroimaging. The most common being the widening of the sylvian fissure, cerebral atrophy, and white matter abnormalities.

Conclusion. Although newborn screening of GA1 and initiation of early management of this condition have been seen important, it is still prudent to continue the appropriate management and to provide timely aggressive emergency treatment in order to improve outcome of patients with GA1. With the recent Philippine Health Insurance (PhilHealth) coverage of the expanded newborn screening, it is expected that physicians will encounter more of the metabolic disorders, including GA1. Hence, it is important that physicians be more aware of the presenting signs and symptoms of this disorder, as well as its management, which can further improve the neurologic and developmental outcomes of these patients.

Key Words: Glutaric aciduria Type 1, expanded newborn screening, GA1

Paper presented at the $13^{\text {th }}$ Asia Pacific Conference on Human Genetics, November 7-9, 2019, Makati Shangri-La, Manila, Philippines.

Corresponding author: Ebner Bon G. Maceda, MD

Division of Clinical Genetics

Department of Pediatrics

Philippine General Hospital

University of the Philippines Manila

Taft Avenue, Manila 1000, Philippines

Email: egmaceda@up.edu.ph

\section{INTRODUCTION}

Glutaric Aciduria Type 1 (GA1) is a rare autosomal recessive organic aciduria. It was first described in 1975 wherein 2 siblings presented with a distinctive neurodegenerative disorder associated with massive glutaric aciduria. ${ }^{1}$ Worldwide, it has a prevalence of approximately 1 in $100,000 .^{2}$ In the Asian population, the prevalence is very 
varied ranging from 1 in 4,896 in the Indian State of Andra Pradesh; 1 in 45,000 in Singapore; to 1 in 202,127 in Japan. ${ }^{3}$ In the Philippines, there are no prevalence studies yet but the first two cases of GA1 in the country were reported in 2011. ${ }^{4}$ In December 2014, the Philippine newborn screening program started offering the expanded newborn screening. This included screening of metabolic disorders, which include GA1. As of December 2018, the cumulative prevalence of GA1 in the Philippines, based on the data of the newborn screening reference center, is 1:95,083 screened neonates. ${ }^{5}$

GA1 is an inborn error of metabolism detected by the expanded newborn screening of the Philippines. This inborn error of metabolism is caused by a deficiency in an enzyme called glutaryl-CoA dehydrogenase which is important in the catabolism of lysine, hydroxylysine and tryptophan. Deficiency of this enzyme causes accumulation of glutaric acid and glutaconic acid. Build-up of glutaric acid in the brain has a cytotoxic effect and subsequently causes cerebral atrophy and brain damage. ${ }^{6}$ This in turn causes the neurologic symptoms of untreated patients, which include dystonia, seizures, and developmental regression. Before the era of newborn screening in the country, this disorder was not recognized. Local physicians, in general, are not familiar with the recognition and management of this rare disease. Management of these cases are limited to those hospitals with a geneticist or a metabolic specialist familiar with the disorder. With the increasing coverage of ENBS, familiarization of its recognition is very important.

Hence, this study aimed to provide a more detailed report on the local data on Filipino GA1 patients in order to inform the medical community about its existence in the Filipino population. Early diagnosis of GA1 is very critical since aggressive management in the pre-symptomatic period may prevent the progressive and irreversible neurological damage and reduce radiologically and clinically evident basal ganglia injury.,

\section{METHODS}

\section{Research design and Setting}

This study was approved by the University of the Philippines Manila Research Ethics Board. It involved a review of medical records of GA 1 cases seen by the Division of Clinical Genetics, Department of Pediatrics, Philippine General Hospital. Participants were identified from the list of GA1 patients of the Division of Clinical Genetics of the Department of Pediatrics, PGH.

Charts of GA1 patients were retrieved and reviewed. The patients were grouped as to either patients with complete work-up or patients with incomplete work-up.

Patients with complete work-up were the GA1 patients who had a developmental assessment by a developmental pediatrician, neurologic assessment by a pediatric neurologist, and cranial imaging. For these patients, the charts were reviewed and analyzed. One patient, on the other hand, had an incomplete work-up due to the absence of a formal developmental assessment by a developmental pediatrician. Unfortunately, the patient already expired years ago.

Information regarding clinical data was kept under lock and key in the Clinical Genetics Unit of the Institute of Human Genetics wherein only the study proponent had access. The database contained information such as subjects' names, addresses, ages, and diagnoses. This information was kept secure by a protected password and access to personal identifiers was limited to the study proponent only.

\section{Study Participants}

This study involved a review of charts and examination of Filipino patients confirmed to have GA1 from January 2010 until December 2017. The diagnoses were based on either clinical presentation or ENBS and were both confirmed by urine organic acids and/or plasma acylcarnitine profiles.

\section{Data collection}

Data on the patients' anthropometrics, date of birth, date of diagnosis, date of the first symptoms and clinical features such as neurologic signs were obtained from the medical records of the Philippine General Hospital and the Institute of Human Genetics, National Institutes of Health-Manila (IHG-NIH) using a data collection form. Biochemical parameters, developmental assessment, neurologic assessment, and radiologic features were reviewed. Biochemical parameters included results of newborn screening from dried blood spots via tandem mass spectrometry, plasma acylcarnitine profiles via liquid-chromatography-tandem mass spectrometry and urinary organic acid profiles via gas chromatography/mass spectrometry. Neuroimaging findings, either via cranial computed tomography (CT) scan or magnetic resonance imaging (MRI), were also recorded. Formal developmental assessment was done using the Batelle Developmental Inventory (BDI) second edition.

\section{Method of data analysis}

Quantitative patient characteristics were summarized by means and standard deviations (SDs). Qualitative characteristics such as clinical features and radiologic findings were presented as a frequency distribution.

\section{RESULTS}

There were a total of 7 patients with Glutaric Aciduria Type 1 at the PGH from January 2010 to December 2017. Of the 7 patients, 6 are living and 1 was deceased due to a systemic infection. Patients 1, 2, 4, and 7 were diagnosed by ENBS (Table 1). Patients 3, 5, and 6, on the other hand, were not screened and had disease onset prior to diagnosis (Table 2). The mean age of patients at diagnosis was earlier for GA1 patients diagnosed via ENBS by more than a year. The mean age of crisis onset, on the other hand, was earlier for those not screened at 3.3 months of age. 
Table 1. Clinical characteristics of Filipino GA1 patients diagnosed via expanded newborn screening

\begin{tabular}{|c|c|c|c|c|c|c|c|c|c|c|}
\hline Patient & $\begin{array}{c}\text { Year at } \\
\text { diagnosis }\end{array}$ & $\begin{array}{c}\text { Age at } \\
\text { Diagnosis } \\
\text { (months) }\end{array}$ & $\begin{array}{c}\text { Age at } \\
\text { Crisis } \\
\text { Onset } \\
\text { (months) }\end{array}$ & $\begin{array}{l}\text { Associated } \\
\text { Inter-current } \\
\text { Infection/ } \\
\text { vaccination }\end{array}$ & Macrocephaly* & Seizure & Dystonia & $\begin{array}{c}\text { Truncal } \\
\text { Hypotonia }\end{array}$ & $\begin{array}{l}\text { GDD initial } \\
\text { evaluation }\end{array}$ & $\begin{array}{l}\text { GDD on } \\
\text { re-evaluation }\end{array}$ \\
\hline 1 & $2016 \varnothing$ & 1 & 2 & - & - & + & - & - & - & + \\
\hline 2 & $2017 \varnothing$ & 1 & 4 & $\begin{array}{c}\text { Acute } \\
\text { Gastroenteritis } \\
\& \text { Vaccination }\end{array}$ & + & + & + & - & + & + \\
\hline 4 & $2017 \varnothing$ & 1 & 8 & $\begin{array}{c}\text { Acute } \\
\text { Gastroenteritis } \\
\text { Pneumonia }\end{array}$ & - & - & + & + & + & + \\
\hline 7 & $2018 \Phi$ & 1 & - & - & - & - & - & - & - & - \\
\hline Average & & 1 & 4.7 & & & & & & & \\
\hline Frequency & & & & $\begin{array}{c}2 \\
(50 \%)\end{array}$ & $\begin{array}{c}1 / 4 \\
(25 \%)\end{array}$ & $\begin{array}{c}2 / 4 \\
(50 \%)\end{array}$ & $\begin{array}{c}2 / 4 \\
(50 \%)\end{array}$ & $\begin{array}{c}1 / 4 \\
(25 \%)\end{array}$ & $\begin{array}{c}2 / 4 \\
(50 \%)\end{array}$ & $\begin{array}{c}3 / 4 \\
(75 \%)\end{array}$ \\
\hline
\end{tabular}

* - Macrocephaly $\left(>97^{\text {th }}\right.$ percentile) on initial evaluation

$\Phi$ - expanded newborn screening is already available starting 2014

(+)- GDD but with no formal assessment

Table 2. Clinical characteristics of Filipino GA1 patients diagnosed via clinical presentation

\begin{tabular}{|c|c|c|c|c|c|c|c|c|c|c|}
\hline Patient & $\begin{array}{c}\text { Year at } \\
\text { diagnosis }\end{array}$ & $\begin{array}{c}\text { Age at } \\
\text { Diagnosis } \\
\text { (months) }\end{array}$ & $\begin{array}{c}\text { Age at } \\
\text { Crisis } \\
\text { Onset } \\
\text { (months) }\end{array}$ & $\begin{array}{c}\text { Associated } \\
\text { Inter-current } \\
\text { Infection/ } \\
\text { vaccination }\end{array}$ & Macrocephaly* & Seizure & Dystonia & $\begin{array}{c}\text { Truncal } \\
\text { Hypotonia }\end{array}$ & $\begin{array}{l}\text { GDD initial } \\
\text { evaluation }\end{array}$ & $\begin{array}{l}\text { GDD on } \\
\text { re-evaluation }\end{array}$ \\
\hline 3 & $2016 \Phi$ & 6 & 1 & Pneumonia & + & + & + & + & + & + \\
\hline 5 & 2010 & 24 & 7 & Pneumonia & + & + & + & + & + & + \\
\hline 6 & 2011 & 10 & 2 & - & - & + & + & + & $(+)$ & nd \\
\hline Average & & 13.3 & 3.3 & & & & & & & \\
\hline Frequency & & & & $\begin{array}{c}2 / 3 \\
(66.67 \%)\end{array}$ & $\begin{array}{c}2 / 3 \\
(66.67 \%)\end{array}$ & $\begin{array}{c}3 / 3 \\
(100 \%)\end{array}$ & $\begin{array}{c}3 / 3 \\
(100 \%)\end{array}$ & $\begin{array}{c}3 / 3 \\
(100 \%)\end{array}$ & $\begin{array}{c}3 / 3 \\
(100 \%)\end{array}$ & $\begin{array}{c}2 / 2 \\
(100 \%)\end{array}$ \\
\hline
\end{tabular}

nd- no data (deceased patient)

* - Macrocephaly (>97th percentile) on initial evaluation

$\Phi$ - expanded newborn screening is already available starting 2014

(+)- GDD but with no formal assessment

Despite early diagnosis and management, 2 of the 4 (50\%) patients who underwent ENBS had global developmental delay (GDD) on initial developmental assessment. On re-evaluation, 3 of these 4 (75\%) have global developmental delay. Macrocephaly and truncal hypotonia were present in 1 of 4 patients (25\%) while seizures and dystonia were present in 2 of 4 patients (50\%).

Seizure, truncal hypotonia and dystonia were present in all three patients who were not screened. Macrocephaly and global developmental delay were present in 2 of them. Data of formal assessment was lacking for the deceased patient (patient 6), but clinical notes suggested global developmental delay as well.

All patients had a head circumference of $>75^{\text {th }}$ percentile on initial assessment. Four of the 7 patients had concomitant infection prior to the onset of symptoms, such as seizures and dystonia. One of them had vaccination one day prior to disease onset.

On initial formal developmental assessment, 2 patients (patients 1 and 7) were at par with age. Four of the patients (patients 2, 3, 4 and 5) were already with GDD. Adaptive and cognitive domains were primarily affected. Motor domains were affected more than the language domains. On reassessment, only 1 patient was at par with age. The rest have global developmental delay.

The plasma level of C5DC varies in patients from 2.81 to $4.58 \mathrm{umol} / \mathrm{L}$. Grossly elevated levels of urinary glutaric acid were noted in all patients (Table 3). Urinary glutaconic acid and 3-hydroxyglutaric acid were also detected in all patients, either slightly elevated or in trace amounts.

Neuroimaging done on patients with GA1 showed both striatal and extra-striatal findings (Table 4). Two patients, one screened and one unscreened, presented with striatal injuries on neuroimaging done after onset of neurologic symptoms. All of the patients, both screened and unscreened, have extra-striatal abnormalities. (Figures 1 and 2) The expansion of CSF spaces, exemplified by widening of the sylvian fissures (6/7), fronto-temporo-parietal sulci (2/7) and the prominent sub-arachnoid spaces (1/7), was the most common extra-striatal abnormality. Cerebral atrophy and signal abnormalities of the white matter were present in 3 of $7(42.86 \%)$ patients. 

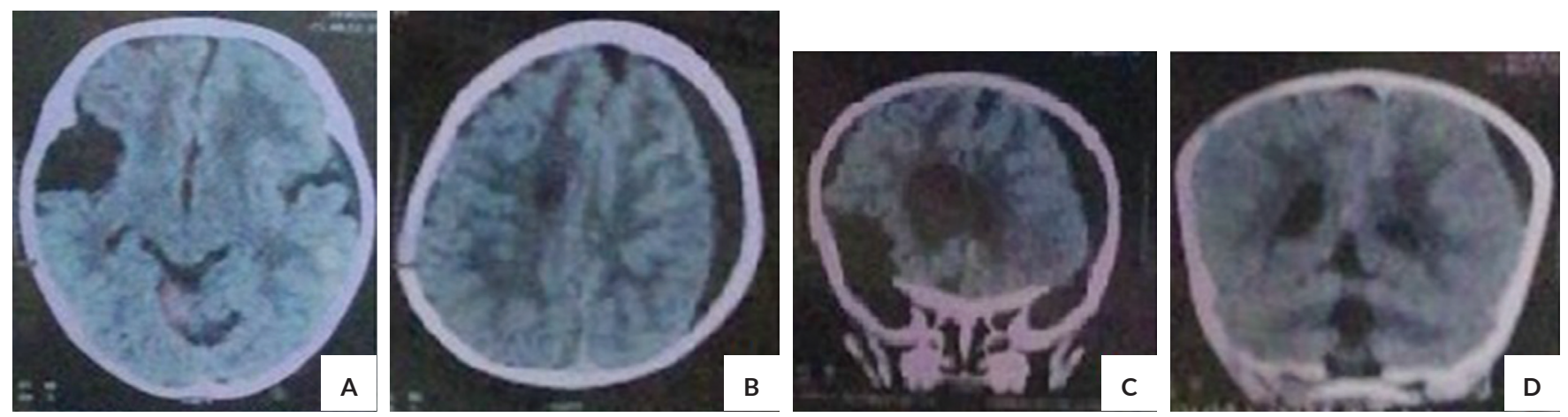

Figure 1. Cranial CT scan images of patient 3 at 5.5 months old. (A) porencephalic cyst right, (B) left frontoparietal subdural effusion. (C) and (D) show fronto-parietal atrophy.
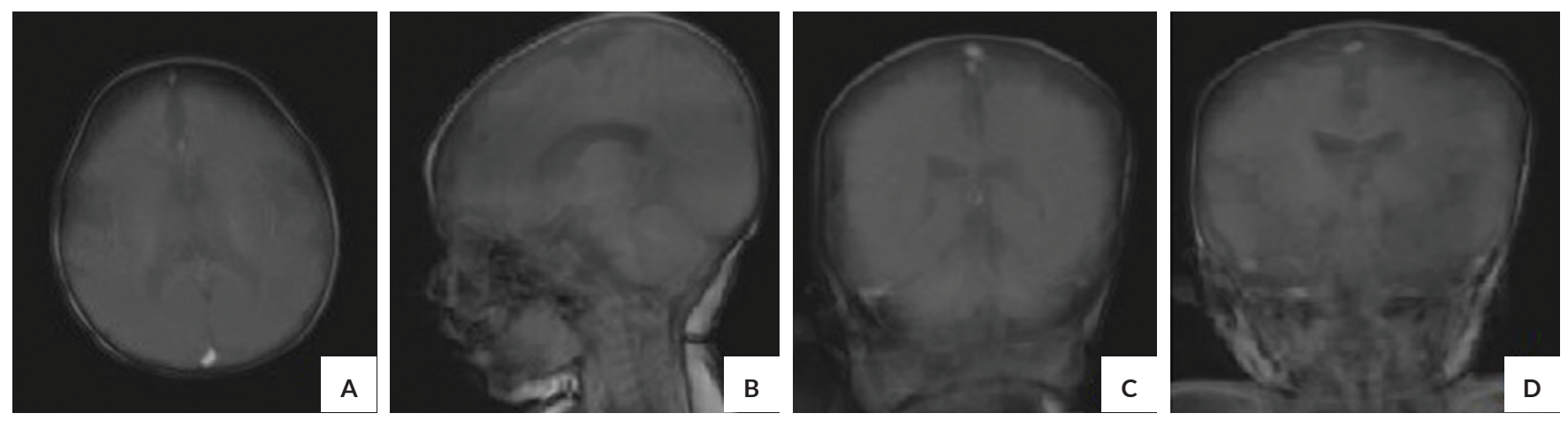

Figure 2. Cranial MRI images of patient 7 at 4.5 months old. (A,B,C,D) show prominent CSF spaces pronounced in the sylvian fissures, bilateral anterior temporal poles, and superior cerebellar cisterns.

Table 3. Biochemical characteristics of GA1 patients obtained from urine organic acid profile, plasma acylcarnitine profile, and expanded newborn screening results

\begin{tabular}{|c|c|c|c|}
\hline \multicolumn{2}{|l|}{ Characteristics } & Patients diagnosed via ENBS & Patients diagnosed by clinical presentation \\
\hline Urinary Organic Acid Profile & & Frequency $(n=4)$ & Frequency $(n=3)$ \\
\hline Glutaric Acid & & $4(100 \%)$ & $3(100 \%)$ \\
\hline Glutaconic Acid & & $4(100 \%)$ & $3(100 \%)$ \\
\hline $30 H G A$ & & $4(100 \%)$ & $3(100 \%)$ \\
\hline Adipate & & $4(100 \%)$ & $3(100 \%)$ \\
\hline Suberate & & 0 & $2(66.67 \%)$ \\
\hline 3-Hydroxyisovalerate & & 0 & 1 (33.33\%) \\
\hline 3-hydroxybutyrate & & 0 & $1(33.33 \%)$ \\
\hline Plasma Acylcarnitine Profile & Reference Value & Mean, (SD) & Mean, (SD) \\
\hline C5DC (umol/L) & $0.02-0.16 \mathrm{umol} / \mathrm{L}$ & $3.64 \pm 0.89$ & nd \\
\hline Expanded Newborn Screening results & Reference Value & Mean $(n=5),(S D)$ & \\
\hline C5DC (umol/L) & $\leq 0.31 \mathrm{umol} / \mathrm{L}$ & $4.55 \pm 2.21$ & \\
\hline C5DC/C4 (umol/L) & $\leq 1.43 \mathrm{umol} / \mathrm{L}$ & $24.47 \pm 9.61$ & \\
\hline C5DC/C8 (umol/L) & $\leq 5.32 \mathrm{umol} / \mathrm{L}$ & $96.89 \pm 28.47$ & \\
\hline C5DC/C12 (umol/L) & $\leq 9.91 \mathrm{umol} / \mathrm{L}$ & $57.27 \pm 11.38$ & \\
\hline C5DC/C16 (umol/L) & $\leq 0.28 \mathrm{umol} / \mathrm{L}$ & $1.84 \pm 0.40$ & \\
\hline C6DC (umol/L) & $\leq 0.24 \mathrm{umol} / \mathrm{L}$ & $1.84 \pm 0.18$ & \\
\hline
\end{tabular}

nd- no done 
Table 4. Neuroimaging characteristics of GA1 patients

\begin{tabular}{|c|c|c|c|c|c|c|c|c|c|}
\hline \multirow[t]{2}{*}{ Characteristics } & \multicolumn{4}{|c|}{ Patients diagnosed via ENBS } & \multicolumn{4}{|c|}{$\begin{array}{l}\text { Patients diagnosed by } \\
\text { clinical presentation }\end{array}$} & \multirow{4}{*}{ Frequency } \\
\hline & Patient 1 & Patient 2 & Patient 4 & Patient 7 & \multirow{3}{*}{ Frequency } & Patient 3 & Patient 5 & Patient 6 & \\
\hline Type of Neuroimaging & CT scan & CT scan & CT scan & MRI & & CT scan & CT scan & MRI & \\
\hline $\begin{array}{l}\text { Age imaging was done } \\
\text { (patient condition) }\end{array}$ & $\begin{array}{c}6 \\
\text { months } \\
\text { (after } \\
\text { crisis) }\end{array}$ & $\begin{array}{c}4.5 \\
\text { months } \\
\text { (after } \\
\text { crisis) }\end{array}$ & $\begin{array}{c}10 \\
\text { months } \\
\text { (after } \\
\text { crisis) }\end{array}$ & $\begin{array}{c}4.5 \\
\text { months } \\
\text { (well) }\end{array}$ & & $\begin{array}{c}5.5 \\
\text { months } \\
\text { (after } \\
\text { crisis) }\end{array}$ & $\begin{array}{c}22 \\
\text { months } \\
\text { (after } \\
\text { crisis) }\end{array}$ & $\begin{array}{c}6 \\
\text { months } \\
\text { (after } \\
\text { crisis) }\end{array}$ & \\
\hline \multicolumn{10}{|l|}{ Striatal Abnormalities } \\
\hline Lacunar infarct (caudate lesion) & + & - & - & - & $1(25 \%)$ & - & - & - & 0 \\
\hline Basal ganglia signal abnormalities & - & - & - & - & 0 & - & + & - & $1(33.33 \%)$ \\
\hline Subthalamic signal abnormalities & - & - & - & - & 0 & - & + & - & $1(33.33 \%)$ \\
\hline \multicolumn{10}{|l|}{ Extra-striatal Abnormalities } \\
\hline Sylvian fissure widening & - & + & + & + & $3(75 \%)$ & + & + & + & $3(100 \%)$ \\
\hline Cerebral atrophy & - & + & + & - & $2(50 \%)$ & + & - & - & $1(33.33 \%)$ \\
\hline Abnormalities of the white matter & + & - & - & + & $2(50 \%)$ & - & - & + & $1(33.33 \%)$ \\
\hline Prominence of cortical sulci & - & + & - & + & $2(50 \%)$ & - & - & - & 0 \\
\hline Brainstem atrophy & - & + & - & - & $1(25 \%)$ & - & + & - & $1(33.33 \%)$ \\
\hline Fluid collection cerebral convexity & - & - & + & - & $1(25 \%)$ & - & + & - & $1(33.33 \%)$ \\
\hline Prominent or dilated ventricles & - & + & + & - & $2(50 \%)$ & - & - & - & 0 \\
\hline Prominent subarachnoid spaces & + & + & - & - & $2(50 \%)$ & - & - & - & 0 \\
\hline Signal abnormalities on the dorsal brainstem & - & - & - & - & 0 & - & + & - & $1(33.33 \%)$ \\
\hline Subdural hematoma & - & - & - & - & 0 & - & - & + & $1(33.33 \%)$ \\
\hline Subdural effusion & - & - & - & - & 0 & + & - & - & $1(33.33 \%)$ \\
\hline Thalamic lesion & - & - & - & - & 0 & - & + & - & $1(33.33 \%)$ \\
\hline Prominent superior cerebellar cistern & - & - & - & + & $1(25 \%)$ & - & - & - & 0 \\
\hline
\end{tabular}

\section{DISCUSSION}

This is a descriptive study of Filipino patients with Glutaric Aciduria Type 1. The first 2 patients with GA1 in the Philippines discussed in a case report in 2011 are included in this study. It has been reported that early diagnosis and initiation of appropriate management of GA1 patients is associated with a better outcome. ${ }^{7}$ Due to the limited number of cases, comparison of outcomes among screened and unscreened patients is hard to do in this small cohort of patients. However, it may still be prudent to compare these patient groups. It is seen in previous studies that the clinical evolution of patients detected by NBS appears to be favourable. ${ }^{8}$

The detection of glutarylcarnitine (C5DC) in dried blood spots (DBS) is the primary marker used for GA1 in ENBS. ${ }^{9}$ For those who underwent ENBS (patients 1, 2, 4, and 7), C5DC was around 14 to 15 times elevated from the reference value. Sensitivity of ENBS via C5DC levels was noted to be about $95 \% .{ }^{8}$ This screening may fail to detect low excretors, which may have normal or only slightly increased C5DC concentrations. Hence, it is advised to repeat a pathologic DBS and be confirmed via one or more alternative techniques. ${ }^{9}$ In the Philippines, the diagnosis for all GA1 patients was done through confirmatory tests namely urine organic acids and/or plasma acylcarnitines. C5DC levels in our patients who underwent plasma acylcarnitine showed elevated values. Urine organic acid profiles showed grossly elevated GA on all patients. This data shows that all our patients had high excretory GA1 profile in the urine. Glutaconic acid and 3OHGA were also noted on all our patients with GA1. Parallel measurement of C5DC, GA and 3OHGA increases specificity of these diagnostics. ${ }^{8}$

Among the clinical features associated with GA1 patients, macrocephaly may be one of the earliest signs. In most reports, macrocephaly is present in $65-75 \%$ of presymptomatic GA1 patients. ${ }^{8}$ In our patients who underwent ENBS, only one had macrocephaly on initial assessment. The other three screened patients had a head circumference $>75^{\text {th }}$ percentile and had no associated signs and symptoms. These patients were started on our treatment protocol for GA1, which include starting patients on a protein-restricted diet (natural protein at 1.5 grams per kilogram per day) and on L-carnitine supplementation at 100 milligrams per kilogram per day. Metabolic dieticians were tapped to provide guidance in the daily dietary needs of our patients adequate to promote growth and development. The patients were also provided with a special milk formula devoid of lysine and tryptophan, to give adequate caloric intake despite protein restriction.

Dystonia, truncal hypotonia and seizures were also common in our GA1 patients after the onset of an acute 
metabolic crisis or a catabolic state. Truncal hypotonia is at $25 \%$ (1 of 4) of screened patients while dystonia and seizures presented in $50 \%$ of screened patients. All unscreened patients had truncal hypotonia, seizure and dystonia. Seizure was apparently a common long-term complication of GA1. In a cohort of South African GA1 patients, seizure is present in $66.67 \%$ of patients. ${ }^{2}$ In our cohort, five patients had seizures $(71.43 \%)$ and it is yet to be assessed if they can be tapered off from anti-epileptic drugs (AEDs) later on. Dystonia, as frequently reported, occur commonly in GA1 patients. It is usually accompanied by truncal hypotonia as well, as in patients $3,4,5$ and $6 .^{2}$ Patients 2,3 , 4, and 5 had dystonia after an illness, like pneumonia or gastroenteritis, and even vaccination. To note, patients 2 and 4 were diagnosed and managed early and pre-symptomatically. This shows that complications can still ensue despite early diagnosis and management. However, even in the absence of a metabolic crisis, onset of dystonia is possible, just like in patient 6; although diagnosis and management for the patient was delayed. ${ }^{9}$ From this data, it is apparent that the features are primarily neurologic. To prevent permanent neurologic injuries and progressive neurologic deterioration, proper precautions and good metabolic control especially during stressful conditions should be enforced. ${ }^{8}$ Also, emergency treatment protocol should be initiated promptly. This includes prevention of the catabolic state by giving high caloric diet, reduction of GA and 3OHGA production by omission of natural protein for 24 to 48 hours, amplification of the physiologic detoxification mechanism and prevention of secondary carnitine depletion by L-carnitine supplementation, and maintenance of normal fluid, $\mathrm{pH}$ and electrolytes via enteral or intravenous fluids. ${ }^{9,10}$

Developmental profiles of our GA1 patients showed that majority had global developmental delay. In a study on the neurodevelopmental profiles of GA1 patients done in 2014, it was seen that GA1 affects fine motor skills and speech, regardless of early treatment and IQ scores. Weaknesses in fine motor were attributed to striatal and fronto-temporal pathology, which were primarily involved in motor skills and motor planning. Speech and language problems were also related to a motor planning deficit which affects oral-motor skills. In addition, it was observed that early neuropsychological and speech assessments and therefore speech therapy improved speech in GA1 patients. ${ }^{11}$ These show that in addition to dietary management and medical therapy initiated in GA1 patients, appropriate therapies can make the outcome of patients more favourable.

Comparing the outcomes of those screened versus those who were not screened, there was a noted difference at diagnosis since two screened patients were initially developmentally at par with age while the unscreened patients had GDD. Also, on initial evaluation of our screened patients, they were all well and presented with no neurologic symptoms. Although this cannot be inferred statistically for now, this can be revisited when a significant number of patients are attained. However, it is quite apparent that early detection and management of our patients may initially improve outcome. Based on the experience of newborn screening of GA1 in Taiwan, it is early diagnosis and full compliance of treatment guidelines which are deemed important to have good outcome. ${ }^{12}$

Radiologic features of GA1 patients can be grouped to either striatal or extra-striatal. Striatal abnormalities, together with macrocephaly and fronto-temporal abnormalities are highly suggestive of GA1. ${ }^{13}$ In patient 1 , there was a note of lacunar infarct in the left caudal nucleus, which is a part of the dorsal striatum. In previous studies, signal changes of the striatum were the most specific MRI abnormalities with acute onset of motor dysfunction. However, this correlation with striatal changes with movement disorders has not been seen. Patient 1 , although with striatal features, does not have dystonia or movement disorders. For those with dystonia, only patient 5 had striatal features. Recent insight on the pathophysiology of dystonia is that it is a circuit disorder and it is not only the basal ganglion which is affected. It also affects the thalamo-cortical connections, the brainstem, and the cerebellum. ${ }^{9}$ At present, although some correlation can be made between the presence of dystonia and the radiologic features, the understanding of the pathophysiology of dystonia is still incomplete. Extra-striatal abnormalities, which are more common in our patients, both screened and unscreened, may be present even without a crisis. Some of these abnormalities are related to age, appear to manifest after a distinct time pattern, and represent a maturational delay resolving with age rather than due to a brain injury. ${ }^{14}$ Hence, these extra-striatal findings may not necessarily be due to a metabolic crisis.

A multidisciplinary approach of care was also given to the patients. Depending on the need, they were advised physical, occupational and speech therapy. In a study on GA1 patients, it was observed that there's improved speech following speech therapy. Hence, it was suggested that patients with neuropsychological and speech assessments be done early on so that early and appropriate intervention may be done. ${ }^{11}$

In addition to carnitine supplementation, anti-dystonia drugs and AEDs had been used in GA1 patients. Of our 7 patients, only patient 5 was prescribed with baclofen, which is one of the most widely used drug for dystonic movements in GA1. Its use, however, is limited for children with prominent axial hypotonia due to worsening of reduced muscle tone. Improvement for our patient is difficult to assess for now as there are compliance issues. For our patients with seizures, Phenobarbital was used for maintenance. Although no study yet has analyzed the effectiveness of AEDs in GA1, the choice of AEDs should still be based from the semiology of the seizure. ${ }^{9}$

There are some identified challenges noted in the care of patients with GA1 in our cohort which might have contributed in the outcome of our screened patients. 
Despite being started on the appropriate management, aggressive emergency treatment was sometimes delayed. It being a rare metabolic condition, patient management was likewise sometimes suboptimal because of financial and compliance issues. Hence, the importance of counselling cannot be over-emphasized at every clinic visit which provides an opportunity to empower the families caring for GA1 patients.

\section{CONCLUSION}

GA1 patients present with macrocephaly, seizures, dystonia, truncal hypotonia, and global developmental delay. Biochemical features include elevated plasma C5DC, and the presence of urinary glutaric acid, glutaconic acid and 3-hydroxyglutaric acid. Radiologic features include striatal and extra-striatal abnormalities on neuroimaging, the most common being the widening of the sylvian fissure, cerebral atrophy, and white matter abnormalities. Although those diagnosed via expanded newborn screening were initially well, majority still had seizures, dystonia, truncal hypotonia, and global developmental delay. This only shows that although appropriate and timely management were initiated, aggressive emergency treatment should never be delayed.

With the data presented on Filipino GA1 patients, a better understanding of the condition is expected to translate into better care. With the full ENBS coverage in the country, it is anticipated that physicians will encounter more of these metabolic disorders, including GA1. Being more cognizant of the presenting signs and symptoms of this disorder, as well as its management, it is foreseen that the neurologic and developmental outcomes of these patients will be improved.

\section{Statement of Authorship}

All authors have approved the final version submitted.

\section{Author Disclosure}

All authors declared no conflicts of interest.

\section{Funding Source}

None.

\section{REFERENCES}

1. Goodman SI, Markey SP, Moe PG, Miles BS, Teng CC. Glutaric aciduria; a new disorder of amino acid metabolism. Biochem Med. 1975 Jan; 12(1):12-21.

2. Govender R, Mitha A, Mubaiwa L. A review of patients with glutaric aciduria type1 at Inkosi Albert Luthuli Central Hospital, Durban, South Africa. S Afr Med J. 2017 Feb; 107(3):201-4.

3. Moorthie S, Cameron L, Sagoo G, Burton H. Birth prevalence of five inherited metabolic disorders: A systematic review. National Institute for Health Research. PHG Foundation, 2013.

4. Fodra EGD, Chiong MAD, Balansay LS, Lanot VO. Biochemical and clinical findings in the first two cases of glutaric aciduria type $\mathrm{I}$ in the Philippines. Acta Med Philipp. 2011; 45(4):70-2

5. NBS Statistics 2018 [Internet]. Newborn Screening Reference Center. [cited 2019 Aug 11]. Available from: newbornscreening.ph

6. Pusti S, Das N, Nayek K, Biswas S. A treatable neurometabolic disorder: glutaric aciduria type 1. Case Rep Pediatr. 2014; 2014:256356.

7. Strauss KA, Puffenberger EG, Robinson DL, Morton DH. Type I glutaric aciduria, part 1: natural history of 77 patients. Am J Med Genet C Semin Med Genet. 2003 Aug; 121C(1):38-52

8. Couce ML, Lopez-Suarez O, Boveda MD, Castiñeiras DE, Cocho JA, Garcia-Villoria J, et al. Glutaric aciduria type I: outcome of patients with early- versus late-diagnosis. Eur J Paediatr Neurol. 2013 Jul; 17(4):383-9.

9. Boy N, Mühlhausen C, Maier EM, Heringer J, Assmann B, Burgard $\mathrm{P}$, et al. Proposed recommendations for diagnosing and managing individuals with glutaric aciduria type I: second revision. J Inherit Metab Dis. 2017 Jan; 40(1):75-101.

10. Kölker S, Christensen E, Leonard JV, Greenberg CR, Boneh $\mathrm{A}$, Burlina $\mathrm{AB}$, et al. Diagnosis and management of glutaric aciduria type I - revised recommendations. J Inherit Metab Dis. 2011 Jun; 34(3):677-94.

11. Brown A, Crowe L, Beauchamp MH, Anderson V, Boneh A. Neurodevelopmental profiles of children with glutaric aciduria type I diagnosed by newborn screening: a follow-up case series. JIMD Rep. 2015; 18:125-34.

12. Tsai FC, Lee HJ, Wang AG, Hsieh SC, Lu YH, Lee MC, et al. Experiences during newborn screening for glutaric aciduria type 1: Diagnosis, treatment, genotype, phenotype, and outcomes. J Chin Med Assoc. 2017 Apr; 80(4):253-61.

13. Harting I, Neumaier-Probst E, Seitz A, Maier EM, Assmann B, Baric I, et al. Dynamic changes of striatal and extra-striatal abnormalities in glutaric aciduria type I. Brain. 2009 Jul; 132(Pt 7):1764-82.

14. Kupier A, Eggink H, Tijssen MAJ, de Koning TJ. Neurometabolic disorders are treatable causes of dystonia. Rev Neurol (Paris). 2016 Aug-Sep; 172(8-9):455-64. 